\title{
Effect of socio demographic and personal factors on infertility and its association with mental health and social support in North Indian population
}

\author{
Neetu Singh, Jyotsna Singh*
}

Department of Obstetrics and Gynecology, Dr. Ram Manohar Lohia Institute of Medical Sciences, Lucknow, India

Received: 9 October 2018

Accepted: 27 October 2018

\section{*Correspondence:}

Dr. Jyotsna Singh,

E-mail: jyotsna.0805@gmail.com

Copyright: () the author(s), publisher and licensee Medip Academy. This is an open-access article distributed under the terms of the Creative Commons Attribution Non-Commercial License, which permits unrestricted non-commercial use, distribution, and reproduction in any medium, provided the original work is properly cited.

\begin{abstract}
Background: Motherhood is a bliss in women's lives and thus infertility is considered as a social stigma. In present study, we measure the effect of socio-demographic and personal factors on infertility as well as the status of social support and mental health in infertile women.

Methods: This was a cross-sectional study comprising 90 infertile women and 90 women in the control group, conducted at Ram Prakash Gupta Memorial Mother and Child State Referral Centre of RMLIMS, Lucknow, India. The questionnaires used were Socio-demographic and personal characteristics, General Health Questionnaire (GHQ12) to assess mental health, Perceived Social Support Questionnaire (PSSQ). To determine the relationship between socio-demographic characteristics, personal characters, mental health, and social support with infertility, Chi-square test was used.

Results: Age, education, and occupation had statistically significant $(\mathrm{p}<0.05)$ relation with infertility, high BMI, and caffeine intake also had the significant adverse effect on fertility outcomes $(p<0.05)$. Infertility patients had poor mental health status (higher mean GHQ-12 score 20.8土4.2) and poor perceived social support (lower mean PSSQ score 29.7 \pm 7.0$)$.

Conclusions: In present study, the socio-demographic factors, lifestyle factors, social support and mental health status is associated with fertility outcomes. Their modifications have the potential to improve reproductive performances. A structured programme of education, social support, and counselling by specialist health professionals should be formulated to improve the quality of life as well as fertility outcomes in infertile patients.
\end{abstract}

Keywords: Infertility, Mental health, Social support, Socio-demographic factors

\section{INTRODUCTION}

Parenthood is believed to be not only a stage of life but also one of the most important developmental tasks with numerous implications for the relationship between the couple and within the whole family system.

The socio-medical problem of infertility is affecting a large number of couples all over the world. Infertility is defined as 'the inability to conceive after 12 months of regular unprotected sexual intercourse'. The incidence of infertility is constantly increasing. Therefore, infertility can be the cause of severe distress in infertile couples and the futile efforts to conceive exert long-term effects on human functioning.

There are numerous variables which may contribute to the development of depression and anxiety in infertile 
women. The researchers found such factors as duration of infertility, the cause of infertility, educational level, age, occupation and pressure from family etc.

These issues are affecting the quality of life of infertile women in many ways. Depressive and anxiety-related symptoms of infertile women are more prominent than those of fertile females.

The measurement of these indicators and the mitigation of underlying distress by adequate psychosocial interventions should be encouraged. ${ }^{1}$ Delaying childbearing based on incorrect perceptions of female fertility could lead to involuntary childlessness.

Education regarding fertility issues is necessary to help men and women make informed reproductive decisions that are based on accurate information rather than incorrect perceptions. $^{2}$

\section{METHODS}

This was a cross-sectional observational study conducted at Ram Prakash Gupta Memorial Mother and child State Referral Centre of RMLIMS, Lucknow, India, from May 2017 to June 2018. A total of 90 infertile women were enrolled in the study for the analysis and comparison was done with a control group of 90 normal women visiting the out-patient department by a customized questionnaire.

The questionnaire used were

- Socio demographic and personal characteristics

- General Health Questionnaire (GHQ-12) to assess mental health

- $\quad$ Perceived Social Support Questionnaire (PSSQ).

GHQ-12 is extensively used screening instrument for common mental disorders and psychiatric well-being, it consists of 12 items (Annexure 1), each one assessing the severity of mental problem over the past few weeks using a 4-point Likert scale (from 0 to 3 ), a total score ranging from 0-36.

The positive items were corrected from 0 (always) to 3 (never) and the negative ones from 3 (always) to 0 (never). Higher scores indicate worse health. Perceived social support questionnaire (Multidimensional Scale of Perceived Social Support) used for evaluating current social scenario about the problem of infertility (Annexure 2).

It consists of 12 items to measure perceived social support from three sources of family, friends, and other important people. The scores ranged from 1 'completely disagree' to 5 'completely agree' using a Likert scale. Minimum score was 12 and maximum 60.
Higher scores indicate greater perceived social support. The inclusion criteria for participation were:

- Confirmed diagnosis of infertility on the part of the women made by a gynaecologist,

- Ineffective efforts to conceive for a period of at least one year prior to the study,

- Age between 18 and 40 years,

- No children and

- Staying in an intimate relationship with a partner.

\section{Exclusion criteria}

- The co-occurrence of serious chronic somatic diseases (such as diabetes, hyperthyroidism), II. The co-occurrence of psychiatric disorders involving delusions or hallucinations and III. Lack of consent to participate.

\section{Statistical analysis}

To compare different nonparametric variables between the two groups, Chi square test was used. For continuous parametric variables, unpaired t test used for comparison of mean of two groups.

Significance level considered $\mathrm{p}$ value $<0.05$ and GraphPad Software (2018) used for statistical analysis.

\section{Ethical consideration}

All participants were informed about the aims of the study and assured about anonymity of personal information. Written and informed consent was taken from each patient.

Ethical committee approval was not applicable as study was non-experimental as advised by Institutional review board.

\section{RESULTS}

\section{Sociodemographic characteristics and their relationship with infertility}

The socio-demographic characters associated with infertility are shown in Table 1 . In present study among the age group of 31 to 40 years, significantly higher number of women $(34.4 \%)$ were found in infertility group, compared to control group $(7.7 \%$, p value <0.05).

In the infertile group of this study, significantly more number $(\mathrm{p}<0.05)$ of women were highly educated $(51.1 \%)$ in comparison to control group $(26.6 \%)$. Forty percent of infertile women were employed, compared to $23.3 \%$ of control group ( $\mathrm{p}$ value $<0.05$ ). 
Table 1: Sociodemographic characteristics and their relationship with infertility.

\begin{tabular}{|c|c|c|c|c|c|c|}
\hline & & \multicolumn{2}{|c|}{ Infertile women } & \multicolumn{2}{|c|}{ Control group } & \multirow{2}{*}{$\mathbf{P}$ value } \\
\hline & & n (number) & $\%$ & $\mathrm{n}$ (number) & $\%$ & \\
\hline \multirow{3}{*}{ Age (years) } & $<20$ & 3 & 3.3 & 5 & 5.5 & \multirow{3}{*}{0.0001} \\
\hline & $21-30$ & 56 & 62.2 & 78 & 86.6 & \\
\hline & $31-40$ & 31 & 34.4 & 7 & 7.7 & \\
\hline \multirow{3}{*}{ Education } & Primary and below & 16 & 17.7 & 29 & 32.2 & \multirow{3}{*}{0.0001} \\
\hline & Secondary & 28 & 31.1 & 37 & 41.1 & \\
\hline & Higher & 46 & 51.1 & 24 & 26.6 & \\
\hline \multirow{2}{*}{ Origin } & Urban & 61 & 67.7 & 52 & 57.8 & \multirow{2}{*}{0.0548} \\
\hline & Rural & 29 & 32.2 & 38 & 42.2 & \\
\hline \multirow{2}{*}{ Occupation } & Employed & 36 & 40 & 21 & 23.3 & \multirow{2}{*}{0.0002} \\
\hline & Housewife & 54 & 60 & 69 & 76.7 & \\
\hline
\end{tabular}

(Chi square test, $\mathrm{p}$ value $<0.05$ significant)

Table 2: Personal parameters and their relationship with infertility.

\begin{tabular}{|c|c|c|c|c|c|c|}
\hline & & \multicolumn{2}{|c|}{ Infertile women } & \multicolumn{2}{|c|}{ Control group } & \multirow[t]{2}{*}{ P value } \\
\hline & & n (number) & $\%$ & n (number) & $\%$ & \\
\hline \multirow{2}{*}{$\begin{array}{l}\text { Relationship duration } \\
\text { (years) }\end{array}$} & $2-4$ & 33 & 36.7 & 72 & 80 & \multirow{2}{*}{0.0001} \\
\hline & $>5$ & 57 & 51.3 & 18 & 20 & \\
\hline \multirow{2}{*}{ Infertility reason } & Known & 54 & 60 & - & - & \\
\hline & Unknown & 36 & 40 & - & - & \\
\hline \multirow{4}{*}{ BMI } & Underweight $<20$ & 11 & 12.2 & 3 & 3.3 & \multirow{4}{*}{0.0001} \\
\hline & Moderate $20-24$ & 32 & 35.5 & 58 & 64.4 & \\
\hline & Overweight $25-29$ & 40 & 44.4 & 28 & 31.1 & \\
\hline & Obese $>30$ & 7 & 7.8 & 1 & 1.1 & \\
\hline \multirow{4}{*}{$\begin{array}{l}\text { Caffeine }(\mathrm{mg} / \text { day }) \\
1 \text { cupcoffee }=100 \mathrm{mg} \\
1 \text { cup tea }=50 \mathrm{mg}\end{array}$} & $0-25$ & 1 & 1.1 & 0 & 0 & \\
\hline & $26-100$ & 33 & 36.7 & 49 & 54.4 & \multirow{3}{*}{0.048 (Yates' corrected } \\
\hline & $101-300$ & 52 & 57.8 & 41 & 45.5 & \\
\hline & $>300$ & 4 & 4.4 & - & - & \\
\hline
\end{tabular}

\section{Personal parameters and their relationship with infertility}

The cause of infertility was identifiable in $60 \%$ women and in $40 \%$ cases it remains unexplained. About fifty one percent of infertile women had greater than five years of relationship duration, compared to $20 \%$ in control group. Among infertility group, $44.4 \%$ were overweight, $7.8 \%$ were obese and $12.2 \%$ were underweight, showing significantly higher incidence of obesity in infertile females $(\mathrm{p}$ value $=0.0001)$. Higher caffeine intake was observed to be linked with infertility as $57.8 \%$ infertile women were consuming 2 to 6 cups of tea per day and $4.4 \%$ were consuming more then 6 cups. Whereas among control group, $45.5 \%$ were consuming 2 to 6 cups of tea per day ( $\mathrm{p}$ value $<0.05$ ).

\section{Relationship of mental health and social support with infertility}

In terms of mental health status, mean GHQ -12 score of infertile groups was significantly higher $(20.8 \pm 4.2)$ compared to control group $(9.1 \pm 3.0$, p value $<0.001)$, indicating poor mental health condition of infertile women. The mean PSSQ score of infertile groups was $29.7 \pm 7.0$ compared to control group $(44.2 \pm 5.6$, p value $<0.001)$, indicating poor social support toward infertile patients.

Table 3: Relationship of mental health and social support with infertility.

\begin{tabular}{|llll|}
\hline & $\begin{array}{l}\text { Infertile } \\
\text { women (mean) }\end{array}$ & $\begin{array}{l}\text { Control group } \\
\text { (mean) }\end{array}$ & $\begin{array}{l}\text { Unpaired } \\
\text { t-test } \\
\text { (p-value) }\end{array}$ \\
\hline $\begin{array}{l}\text { Mental } \\
\text { health }\end{array}$ & $20.8 \pm 4.2$ & $9.1 \pm 3.0$ & 0.0001 \\
\hline $\begin{array}{l}\text { Social } \\
\text { support }\end{array}$ & $29.7 \pm 7.0$ & $44.2 \pm 5.6$ & 0.0001 \\
\hline
\end{tabular}

\section{DISCUSSION}

Age has a very strong relationship with infertility as well as pregnancy outcome, as age advances, the infertility rate also increases. In present study, we observed higher number of infertile women were belonging to older age group compared to control group. Increased infertility in older couples is attributable primarily to decline in 
fertility rates rather than to absolute sterility. ${ }^{3}$ According to the Committee on Gynaecologic Practice of the American College of Obstetrics and Gynaecologists, age is a significant factor influencing a woman's ability to conceive. Social trends have led to deferred childbearing, and an increasing number of women are experiencing age-related infertility and pregnancy loss. Women older than 35 years should receive prompt evaluation and treatment after 6 months of failed attempts to conceive, or earlier if clinically indicated. ${ }^{6}$

In this study, as the infertility rate was more among well educated women, finding appears to support the previous studies. The study presented by Noorbala et al showed higher incidence of psychiatric disorder and unstable personality in infertile patients even with higher education level. ${ }^{5}$ This can be explained by the fact that people with higher education are much aware of the treatment, its complications, and tentative outcomes. There are several other studies, which are not consistent with present study. According to Behrami et al, people with higher education had good mental health $\mathrm{n}$ thus good fertility outcomes. ${ }^{6}$ However future research could better investigate this relationship.

Among employed females participated in present study, higher number of cases were found in infertile group. This finding is in concordance to the studies conducted by Fisher et al and Lakatos et al which showed rate of mental health problems as well as infertility to be higher in employed females. ${ }^{1,7}$ However, Noorbala et al reported poor mental health among housewives than employed females. $^{5}$ The family affects every aspect of an individual's life including work, thus any stress, problems or difficulties in each of these areas can spread to the other area and causes discomfort and dissatisfaction among couples. ${ }^{8}$ In present study, urban or rural background did not have a significant relation with infertility.

Obesity and underweight have an impact on the reproductive function by causing hormonal imbalances and ovulatory dysfunction. Women with BMI >25 and $<19$ usually needs more time to conceive. We also observed the increased incidence of infertility among obese as well as underweight women in this study. These results are comparable with studies conducted by Hassan et al and Norman et al. ${ }^{9,10}$

Caffeine is present in coffee, tea, soft drink and in some foods like chocolate its consumption has been linked with prolonged time to conceive although the mechanism is not clear, it may affect ovulation and corpus luteal function through alterations in hormonal levels and has been associated with higher early follicular E2 levels in females. ${ }^{11,12}$ This contribution to infertility is also observed in present study as, increased caffeine intake was more prevalent among infertile patients. Based on present study the mean of mental health score in infertile women was $20.8 \pm 4.2$ and of the control group was $9.1 \pm$
3.0 which indicated poor mental health among infertile women, however the higher mean score of social support in control group $44.2 \pm 5.6$ than infertility group $29.7 \pm$ 7.0 suggested that as level of social support increases mental health status also improved.

The study conducted by Behjati et al showed about $4 \%$ incidence of psychological disorders among the infertile patients and need provision of psychological health care alongside the medical treatment. ${ }^{13}$ Motherhood is indeed a very crucial part of women's life and failure to achieve this is associated with negative effects such as remarriage, separation, and divorce. ${ }^{14}$ Similarly in present study, we observed the poor mental health status of infertility patients in this underprivileged and health resource constrained North Indian population.

Moreover, the pressure from society and expectations on woman for childbearing is much more than man, they are considered to be solely responsible for infertility and these reasons might explain the presence of poor mental health status in infertile women. Present study reflects the close relationship between social support from family, friends and fertility outcomes. Present study showed poor social support system towards infertile women that may contribute to poor mental health status also. Mental health status starts improving as social support increases. This finding appears to be in favour with the results of studies by Peyravi et al and Riahi et al. ${ }^{15,16}$ Moreover, it is thought that social support acts as a shield against stress and has a moderating role in the incidence or aggravation of depression. ${ }^{17}$

\section{CONCLUSION}

This literature has clearly identified a series of sociodemographic and personal factors that potentially impact fertility outcomes. These factors and social support is associated with mental health and their modifications has the potential to improve reproductive performances. Couples attempting to conceive should be counselled and advised regarding their individual factors. A structured programme of education, support, and access to specialist health professionals should encourage and facilitate the optimal fertility results. This will improve the chances of successful fertility outcomes and minimizing the need for costly and invasive infertility treatment.

\section{Funding: No funding sources \\ Conflict of interest: None declared \\ Ethical approval: Not required}

\section{REFERENCES}

1. Lakatos E, Szigeti JF, Ujma PP, Sexty R, Balog P. Anxiety and depression among infertile women: a cross-sectional survey from Hungary. BMC Women's Health. 2017;17(1):48.

2. Peterson B D, Pirritano M, Tucker L, Lampic C. Fertility awareness and parenting attitudes among 
American male and female undergraduate university students. Hum Reprod. 2012;27(5):1375-82.

3. Dunson DB, Baird DD, Colombo B. Increased Infertility with Age in Men and Women. Obstet Gynecol. 2004;103(1):51-6.

4. The Committee on Gynecologic Practice of the American College of Obstetrics and Gynecologists and the Practice Committee of the American Society for Reproductive Medicine. Age-related fertility decline: a committee opinion. Fertil Steril. 2008;90: 486-7.

5. Noorbala AA, Bagheri Yazdi SA, Mohammad K. The validation of general health questionnaire- 28 as a psychiatric screening tool. Hakim Res J. 2009; 11(4):47-53.

6. Bahrami N, Sattarzadeh N, Ranjbar Koochaksariie F, Ghojazadeh M. Comparing depression and sexual satisfaction in fertile and infertile couples. Medical J Reproduct Infertil. 2007;8(1):52-9.

7. Fisher J. Infertility and assisted reproduction. In: Astbury J, Mello MC, Cottingham J, Fisher J, Izutsu T, Pinel A, Saxena S, editors. Mental health aspects of women's reproductive health: a global review of the literature. Geneva: World Health Organization; 2009. p. 128-46.

8. Amponsah MO. Workstress and marital relations. Educational Res 2010;2(1):757-64.

9. Hassan MA and Killick SR. Negative lifestyle is associated with a significant reduction in fecundity. Fertil Steril. 2004;81(2):384-92.

10. Norman RJ, Noakes M, Wu R, Davies MJ, Moran L and Wang JX. Improving reproductive performance in overweight/obese women with effective weight management. Hum Reprod Update 2004;10(3):26780 .

11. Klonoff-Chohen H, Bleha J and Lam-Kruglick P. A prospective study of the effects of female and male caffeine consumption on the reproductive endpoints of IVF and gamete intra-Fallopian trnasfer. Hum Reprod 2002;17(7):1746-54.

12. Lucero J, Harlow BL, Barbieri RL, Sluss $P$ and Cramer DW. Early follicular phase hormone levels in relation to patterns of alcohol, tobacco, and coffee use. Fertil Steril 2001;76(4):723-9.

13. Ardekani ZB, Akhondi MM, Kamali K, Khalaf ZF, Eskandari S, Ghorbani B. Mental health status of patients attending avicenna infertility clinic. J Reproduct Infertil. 2010;11(4).

14. Khodakarami N, Seddig S, Hashemi S, Hamdieh M, Taheripanah R. The disregarded rights of infertility: a phenomenological study. Iranian $\mathrm{J}$ Med Ethics History Med 2009;2(3):39-50.

15. Peyravi H, Hajebi A, Panaghi L. A survey on the relation between social support and mental health in students of Tehran University. J Health System Res. 2010;6(2):301-7.

16. Riahi ME, Aliverdinia A, Pourhossein Z. Relationship between social support and mental health. Social Welfare (Quarterly). 2011;10(39):85122.

17. Bakhshani N, Birashk B, Atefvahid M, Bolhari J. Relationship between perceived social support and stressful life events with depression. Andishe va Rafter. 2003;9(2):49-55

Cite this article as: Singh N, Singh J. Effect of socio demographic and personal factors on infertility and its association with mental health and social support in North Indian population. Int J Reprod Contracept Obstet Gynecol 2018;7:5088-92. 